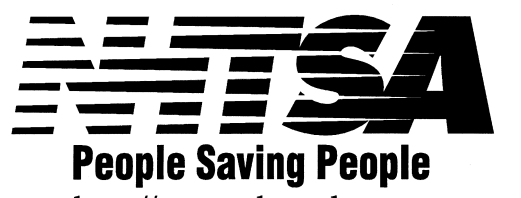

\title{
Effects of Obesity on Seat Belt Fit
}

\author{
Matthew P. Reed \\ Sheila M. Ebert-Hamilton \\ Jonathan D. Rupp \\ University of Michigan Transportation Research Institute
}

July 2011 
Technical Report Documentation Page

\begin{tabular}{|c|c|c|c|}
\hline $\begin{array}{l}\text { 1. Report No. } \\
\text { UMTRI-2011-27 }\end{array}$ & 2. Government Accession No. & \multicolumn{2}{|c|}{ 3. Recipient's Catalog No. } \\
\hline \multirow{2}{*}{\multicolumn{2}{|c|}{$\begin{array}{l}\text { 4. Title and Subtitle } \\
\text { Effects of Obesity on Seat Belt Fit }\end{array}$}} & \multicolumn{2}{|l|}{$\begin{array}{l}\text { 5. Report Date } \\
\text { July } 2011\end{array}$} \\
\hline & & \multicolumn{2}{|c|}{ 6. Performing Organization Code } \\
\hline \multicolumn{2}{|c|}{$\begin{array}{l}\text { 7. Author(s) } \\
\text { Reed, Matthew P., Ebert-Hamilton, Sheila M., and Rupp, J.D. }\end{array}$} & \multicolumn{2}{|c|}{ 8. Performing Organization Report No. } \\
\hline \multirow{2}{*}{\multicolumn{2}{|c|}{$\begin{array}{l}\text { 9. Performing Organization Name and Address } \\
\text { University of Michigan Transportation Research Institute } \\
\text { 2901 Baxter Rd. } \\
\text { Ann Arbor MI } 48109\end{array}$}} & \multicolumn{2}{|c|}{ 10. Work Unit No. (TRAIS) } \\
\hline & & \multicolumn{2}{|c|}{ 11. Contract or Grant No. } \\
\hline \multirow{2}{*}{\multicolumn{2}{|c|}{$\begin{array}{l}\text { 12. Sponsoring Agency Name and Address } \\
\text { National Highway Traffic Safety Administration }\end{array}$}} & \multicolumn{2}{|c|}{ 13. Type of Report and Period Covered } \\
\hline & & \multicolumn{2}{|c|}{ 14. Sponsoring Agency Code } \\
\hline \multicolumn{4}{|l|}{ 15. Supplementary Notes } \\
\hline \multicolumn{4}{|c|}{$\begin{array}{l}\text { 16. Abstract } \\
\text { Obesity has been shown to increase the risk of some types of injury in crashes. One hypothesis is that obesity } \\
\text { adversely effects belt fit by changing the routing of the belt relative to the underlying skeletal structures. To } \\
\text { evaluate this hypothesis, belt fit was measured in a laboratory study of } 54 \text { men and women, } 48 \text { percent of whom } \\
\text { were obese, with a body mass index (BMI) of } 30 \mathrm{~kg} / \mathrm{m}^{2} \text { or greater. Test conditions included a wide range of } \\
\text { upper and lower belt anchorage locations and ranges of seat height, seat cushion angle, and seat back angle } \\
\text { spanning a large fraction of current vehicle front and rear seats. In some conditions, foot position was restricted } \\
\text { to simulate the typical situation in the second row of a small sedan. Across individuals, an increase in BMI of } \\
\text { 10-kg/m }{ }^{2} \text { was associated with a lap belt positioned } 43 \mathrm{~mm} \text { further forward and } 21 \mathrm{~mm} \text { higher relative to the } \\
\text { anterior-superior iliac spines of the pelvis. Each } 10-\mathrm{kg} / \mathrm{m}^{2} \text { increase in BMI was associated with an increase in lap } \\
\text { belt webbing length of } 130 \mathrm{~mm} \text {. The worsening of lap belt fit with restricted foot position was slightly greater } \\
\text { for obese participants. Obesity was associated with a more-inboard shoulder belt routing across a wide range of } \\
\text { upper belt anchorage locations, and the shoulder belt webbing length between the D-ring and latchplate increased } \\
\text { by an average of } 60 \text { mm with each } 10-\mathrm{kg} / \mathrm{m}^{2} \text { increase in BMI. The results suggest that obesity effectively } \\
\text { introduces slack in the seat belt system by routing the belt further away from the skeleton. Particularly in frontal } \\
\text { crashes, but also in rollovers and other scenarios, this slack will result in increased excursions and an increased } \\
\text { likelihood and severity of contacts with the interior. The higher routing of the lap belt with respect to the pelvis } \\
\text { also increases the likelihood of submarining in frontal crashes. }\end{array}$} \\
\hline $\begin{array}{l}\text { 17. Key Word } \\
\text { Belt fit, obesity }\end{array}$ & 18. Distributio & ement & \\
\hline 19. Security Classif. (of this report) & 20. Security Classif. (of this page) & $\begin{array}{l}\text { 21. No. of } \\
\text { Pages }\end{array}$ & 22. Price \\
\hline
\end{tabular}

Form DOT F 1700.7 (8-72) Reproduction of completed page authorized 


\section{Metric Conversion Chart}

APPROXIMATE CONVERSIONS TO SI UNITS

\begin{tabular}{|c|c|c|c|c|c|c|c|c|}
\hline SYMBOL & \multicolumn{4}{|c|}{ WHEN YOU KNOW } & \begin{tabular}{|} 
MULTIPLY \\
BY
\end{tabular} & \multicolumn{2}{|c|}{ TO FIND } & SYMBOL \\
\hline \multicolumn{9}{|c|}{ LENGTH } \\
\hline In & \multicolumn{4}{|c|}{ inches } & 25.4 & \multicolumn{2}{|l|}{ millimeters } & $\mathrm{mm}$ \\
\hline Ft & \multicolumn{4}{|c|}{ feet } & 0.305 & \multicolumn{2}{|l|}{ meters } & $\mathrm{m}$ \\
\hline Yd & \multicolumn{4}{|c|}{ yards } & 0.914 & \multicolumn{2}{|l|}{ meters } & $\mathrm{m}$ \\
\hline Mi & \multicolumn{4}{|c|}{ miles } & 1.61 & \multicolumn{2}{|l|}{ kilometers } & $\mathrm{km}$ \\
\hline \multicolumn{9}{|c|}{ AREA } \\
\hline in $^{2}$ & \multicolumn{4}{|c|}{ squareinches } & \multicolumn{3}{|c|}{ square millimeters } & $\mathrm{mm}^{2}$ \\
\hline $\mathrm{ft}^{2}$ & \multicolumn{2}{|c|}{ squarefeet } & \multicolumn{2}{|c|}{0.093} & \multicolumn{3}{|c|}{ square meters } & $\mathrm{m}^{2}$ \\
\hline$y^{2}{ }^{2}$ & \multicolumn{2}{|c|}{ square yard } & \multicolumn{2}{|c|}{0.836} & \multicolumn{3}{|c|}{ square meters } & $\mathrm{m}^{2}$ \\
\hline Ac & \multicolumn{2}{|c|}{ acres } & \multicolumn{2}{|c|}{0.405} & \multicolumn{3}{|l|}{ hectares } & ha \\
\hline $\mathbf{m i}^{2}$ & \multicolumn{2}{|c|}{ square miles } & \multicolumn{2}{|c|}{2.59} & \multicolumn{3}{|c|}{ square kilometers } & $\mathrm{km}^{2}$ \\
\hline \multicolumn{9}{|c|}{ VOLUME } \\
\hline \multicolumn{3}{|c|}{ fl oz } & id & 29.57 & mill & iliters & $\mathrm{mL}$ & \\
\hline & gal & & lons & 3.785 & liter & & $\mathrm{L}$ & \\
\hline & $\mathrm{ft}^{3}$ & & & 0.028 & cubi & ic meters & $\mathrm{m}^{3}$ & \\
\hline & $d^{3}$ & & & 0.765 & cubi & ic meters & $\mathrm{m}^{3}$ & \\
\hline NOTE: vo & umes & er th & n 100 & $00 \mathrm{~L} \mathrm{sh}$ & be shown in $\mathrm{m}$ & & & \\
\hline & & & & & MASS & & & \\
\hline & $\mathbf{z}$ & & & 28.35 & & grams & g & \\
\hline & b & & nds & 0.454 & & kilograms & $\mathrm{kg}$ & \\
\hline & $\mathbf{T}$ & $\begin{array}{l}\mathrm{sh} \\
\text { to } \\
(2 \\
\mathrm{lb}\end{array}$ & & 0.907 & & $\begin{array}{l}\text { megagrams } \\
\text { (or "metric } \\
\text { ton") }\end{array}$ & Mg (or "t" & \\
\hline & & & & MPER & URE (exact de & egrees) & & \\
\hline & & Fah & nheit & & $\begin{array}{l}5(F-32) / 9 \\
\text { or }(F-32) / 1.8\end{array}$ & Celsius & ${ }^{\circ} \mathrm{C}$ & \\
\hline & & & FOR & RCE an & PRESSURE or & STRESS & & \\
\hline ll & & oour & force & 4.45 & & & ewtons & $\mathrm{N}$ \\
\hline lbf & & $\begin{array}{l}\text { pour } \\
\text { pers }\end{array}$ & $\begin{array}{l}\text { force } \\
\text { dare }\end{array}$ & 6.89 & & & ilopascals & $\mathrm{kPa}$ \\
\hline
\end{tabular}




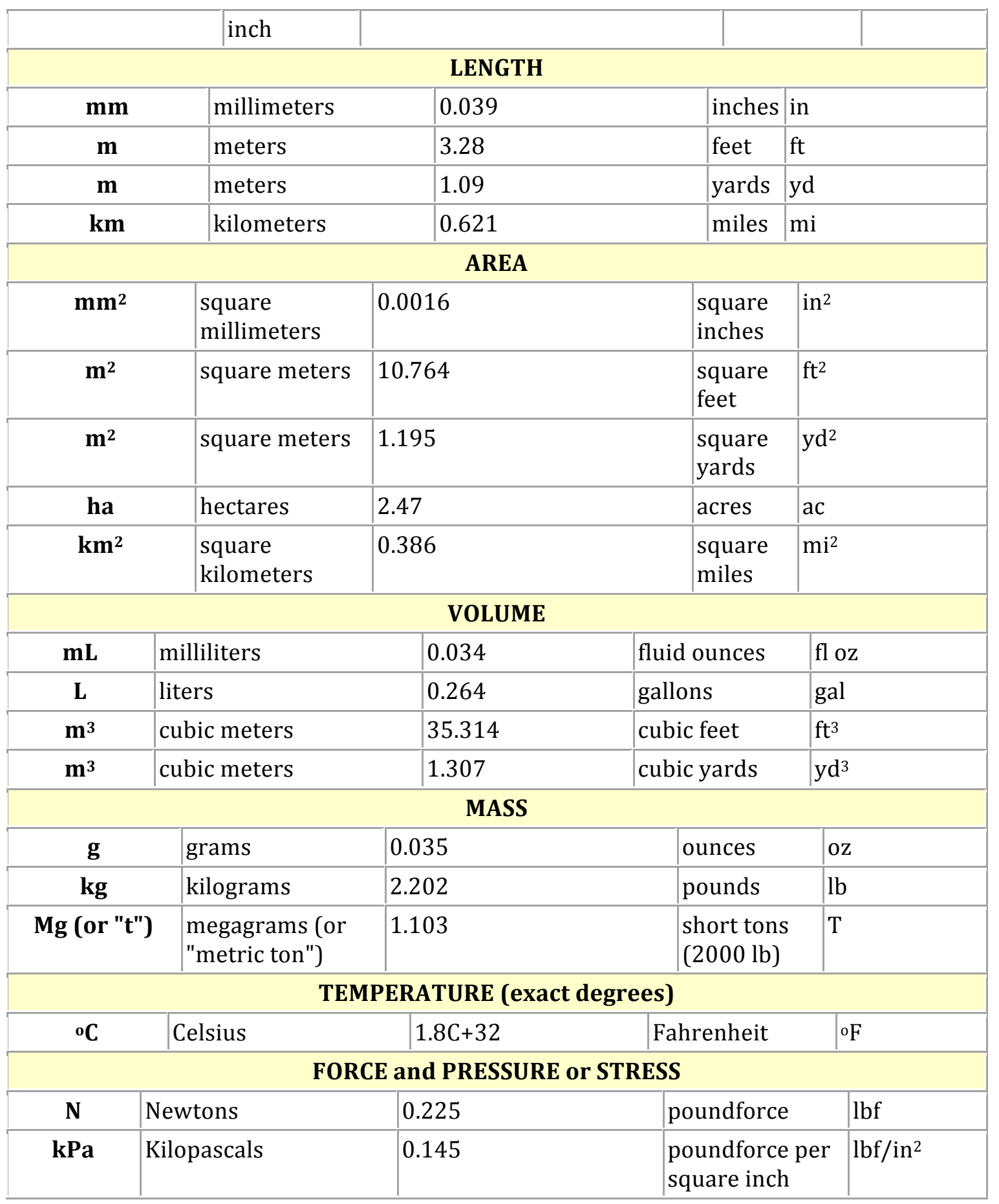

*SI is the symbol for the International System of Units. Appropriate rounding should be made to comply with Section 4 of ASTM E380.

(Revised March 2003) 


\section{ACKNOWLEDGMENTS}

The data collection portion of the study was funded by Transport Canada. The current analysis was funded by the National Highway Traffic Safety Administration under cooperative agreement DTNH22-10-H-00288 with the University of Michigan. 


\section{CONTENTS}

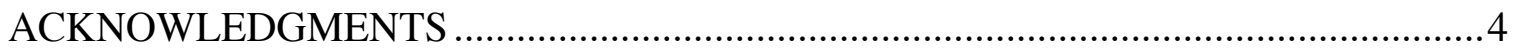

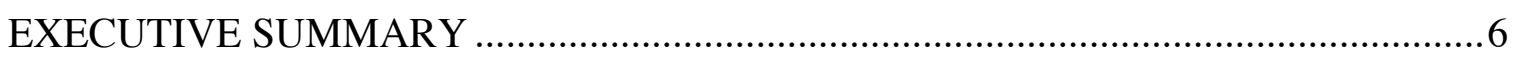

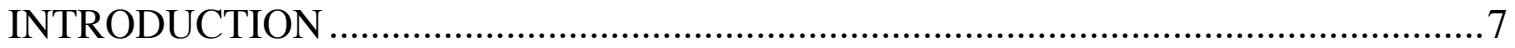

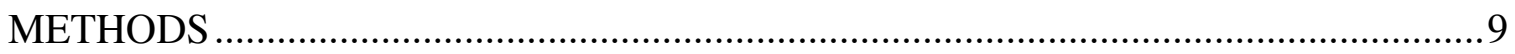

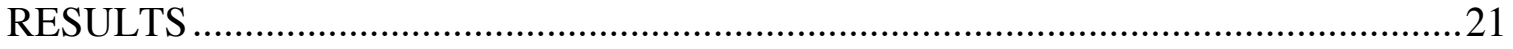

DISCUSSION

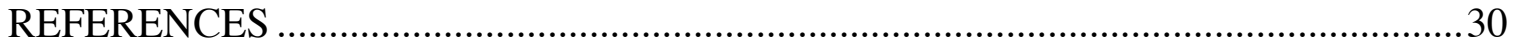




\section{EXECUTIVE SUMMARY}

Obesity has been shown to increase the risk of some types of injury in crashes. One hypothesis is that obesity adversely effects belt fit by changing the routing of the belt relative to the underlying skeletal structures. To evaluate this hypothesis, belt fit was measured in a laboratory study of 54 men and women, 48 percent of whom were obese, with a body mass index (BMI) of $30 \mathrm{~kg} / \mathrm{m}^{2}$ or greater. Test conditions included a wide range of upper and lower belt anchorage locations and ranges of seat height, seat cushion angle, and seat back angle spanning a large fraction of current vehicle front and rear seats. In some conditions, foot position was restricted to simulate the typical situation in the second row of a small sedan. Across individuals, an increase in BMI of $10-\mathrm{kg} / \mathrm{m}^{2}$ was associated with a lap belt positioned $43 \mathrm{~mm}$ further forward and $21 \mathrm{~mm}$ higher relative to the pelvis. Each $10-\mathrm{kg} / \mathrm{m}^{2}$ increase in BMI was associated with an increase in lap belt webbing length of $130 \mathrm{~mm}$. The worsening of lap belt fit with restricted foot position was slightly greater for obese participants. Obesity was associated with a more-inboard shoulder belt routing across a wide range of upper belt anchorage locations, and the shoulder belt webbing length between the D-ring and latchplate increased by an average of $60 \mathrm{~mm}$ with each $10-\mathrm{kg} / \mathrm{m}^{2}$ increase in BMI. The results suggest that obesity effectively introduces slack in the seat belt system by routing the belt further away from the skeleton. Particularly in frontal crashes, but also in rollovers and other scenarios, this slack may result in increased excursions and an increased likelihood and severity of contacts with the interior. The higher routing of the lap belt with respect to the pelvis also may increase the likelihood of submarining in frontal crashes. 


\section{INTRODUCTION}

Approximately 34 percent of U.S. adults are now obese, defined as a body mass index (BMI) of $30 \mathrm{~kg} / \mathrm{m}^{2}$ or higher ${ }^{1}$ (Flegal et al. 2010). Obesity has been shown to increase the risk of death and certain types of injuries to occupants involved in motor-vehicle crashes, notably fractures of the lower extremities and spine in frontal crashes (Zhu et al. 2006, Rupp in press).

Biomechanical reasons for the effects of obesity on injury in frontal crashes were explored in a series of crash tests in which 3-point belt restrained obese and normal BMI cadavers in second-row vehicle seats were subjected to a $48 \mathrm{~km} / \mathrm{h}$ frontal impact crash pulse (Kent et al. 2010). Results of these tests indicated that even with optimal belt positioning over the anterior pelvis, obese cadavers experienced approximately $250 \mathrm{~mm}$ more hip excursion and approximately $200 \mathrm{~mm}$ more knee excursion than non-obese cadavers. Higher hip and knee excursions are associated with an increased likelihood of lower extremity injury from knee contact with forward vehicle structures (Adomeit et al. 1975). Moreover, Kent et al. (2010) demonstrated that the poor occupant kinematics observed in testing with obese cadavers were associated with severe injuries due to belt interaction.

The primary reason for the increased excursion associated with obesity for belted occupants is that the lap and torso belts must deflect greater amounts of soft tissue before they can apply restraint forces to the underlying bony anatomy on the anterior pelvis and shoulder/thorax. However, the increased stretch of the belt webbing associated with higher restraint forces needed to decelerate a higher-mass occupant also likely contributes to increased excursion.

The results of the Kent et al. study indicate that designing restraint systems that provide the same level of protection for obese and normal BMI occupants is likely to be difficult. One factor that compounds this difficulty is that the effects of obesity on seat belt fit (i.e. the position of the belt relative to the bony structures on the anterior pelvis and thorax that it is intended to load) are unknown. Studies of belt fit on seated pregnant women demonstrate that a protruding anterior abdominal contour can shift the lap belt above the pelvis (Klinich et al 1999). This change in belt geometry is of particular concern because it has the potential to further exacerbate the increases in crash-induced hip and knee excursion associated with obesity.

In a previous study, UMTRI researchers developed belt-fit-measurement components for the SAE J4002 H-point manikin, known as the ASPECT manikin or HPM-II (Reed et al. 2002). The ASPECT-BTD, shown in Figure 1, was designed to provide repeatable measurements of lap and shoulder belt fit. As part of that research, a laboratory study was

1 Body mass index is calculated by dividing lightly clothed body weight in $\mathrm{kg}$ by the square of stature (erect standing height) in meters. 
conducted to measure posture and belt fit from 68 men and women, of whom $60 \%$ were obese. Due to funding restrictions, the data have not previously been analyzed.

In the current study, the belt fit data from a subset of the conditions in the original study were analyzed to quantify the effects of body size, particularly BMI, on belt fit. Following the design of the test matrix, separate analyses were conducted for lap and torso belt fit. 


\section{METHODS}

\section{Facilities}

A laboratory mockup of a vehicle seating position was constructed, as shown in Figure 1. The mockup included a front bucket seat from a mid-1990s Saturn, selected because it has minimal contouring and a low backrest that facilitates close placement of the D-ring to the participant. The seat was mounted on a tilting platform that can produce a wide range of seat cushion angles. Seat height was varied by placing wooden platforms with a range of heights beneath the feet of the participant.

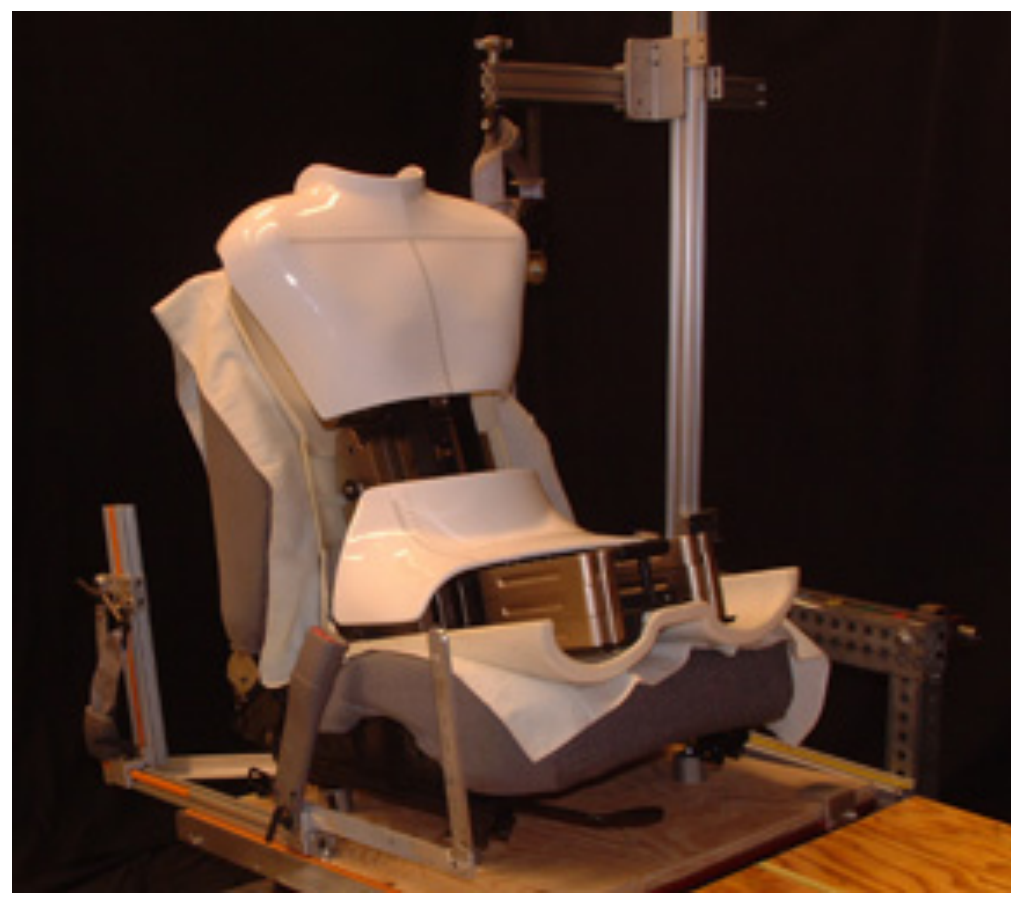

Figure 1. Laboratory mockup showing seat, belt-fit test device (Reed et al. 2002), and adjustable belt hardware.

A seatbelt from the driver position of a 2000 Ford Taurus was used in testing. This belt system is equipped with an emergency locking retractor (ELR) that was free to move (unlocked) throughout testing. The belt system had a sliding latchplate that did not lock or cinch in position with respect to the belt webbing. The D-ring was attached to an adjustable-fixture that could be moved fore-aft, up-down, and laterally with respect to the participant. The D-ring was attached to an assembly that pivoted on a vertical axis so that orientation of the D-ring pivot could be adjusted. In this study, the D-ring pivot was always oriented laterally, simulating a typical B-pillar installation. The buckle was mounted on a rigid stalk. The stalk and outer lower anchorage were mounted to rails that permitted them to be adjusted fore-aft over a wide range.

Coordinate data were collected using a FARO Arm coordinate measurement machine, shown in Figure 2. The FARO Arm is capable of measuring points in 3D space to sub- 
millimeter accuracy. The FARO Arm was aligned to the laboratory coordinate system and its calibration checked as part of the data collection with each participant.

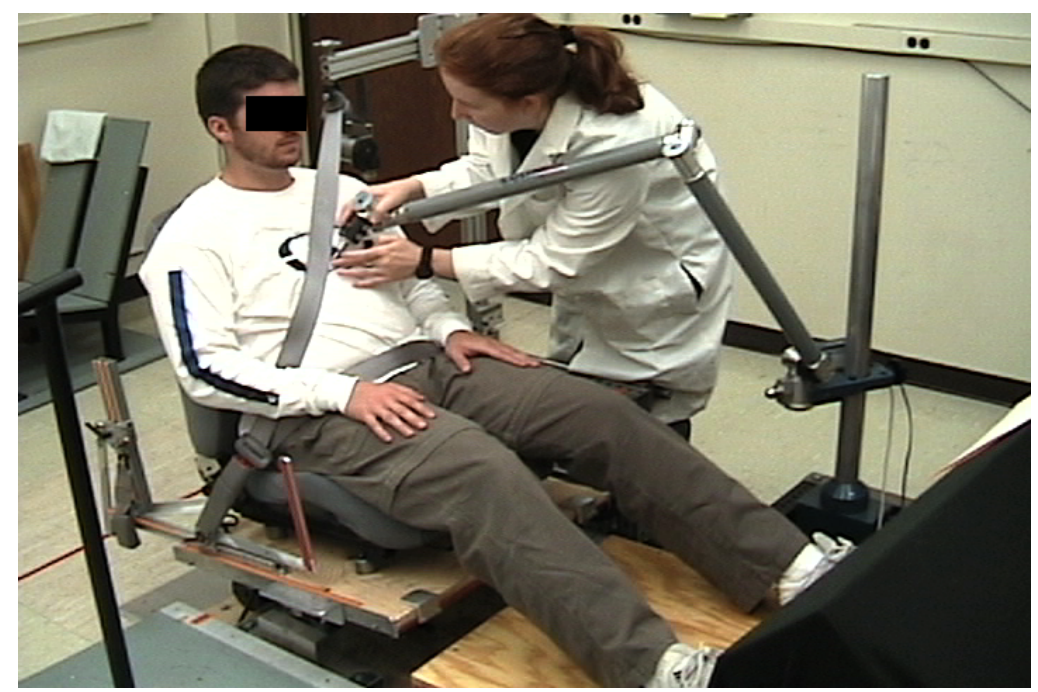

Figure 2. FARO Arm used to record target coordinates.

\section{Test Conditions}

\section{Lap Matrix}

The lap belt test matrix was developed by manipulating levels of cushion angle (SAE A27 of 7.5, 14.5, and 18 degrees), seat height (SAE H30 of 180, 270, and $360 \mathrm{~mm}$ ), belt anchorage location (three levels), and foot position (unrestricted or restricted). The combinations of test conditions represent seat cushion and belt geometries that span the range of rear and front seat geometries and seat heights that are typical of small cars, midsize sedans, and vans.

Belt anchorage locations were selected to produce particular side-view angles of the vector from the anchorage to $\mathrm{H}$-point, a standard seat reference point defined and measured with the SAE J826 H-point manikin (SAE 2011). The selected positions produce angles of 85, 60, and 40 degrees with respect to horizontal for the fore, mid, and aft anchorage locations, respectively, as defined by Federal Motor Vehicle Safety Standard (FMVSS) 210. The outboard and buckle anchorages were moved to the same fore-aft and vertical location with respect to H-point for the fore, mid, and aft conditions.

The restricted foot position required the participants to place their feet flat on the floor and to move them maximally rearward, toward the seat, simulating a rear-seat condition with minimal legroom. Since the goal of this condition was to evaluate belt fit with the knees raised, the restricted foot position was used only at the lowest seat height, which maximized the knee-raising effect. 
Table 1

Lap Test Matrix

\begin{tabular}{cccccc}
\hline $\begin{array}{c}\text { Condition } \\
\text { Number }\end{array}$ & $\begin{array}{c}\text { Buckle } \\
\text { Mounting }\end{array}$ & Foot Position & $\begin{array}{c}\text { Cushion } \\
\text { Angle } \\
\text { (SAE A27) } \\
\text { (degrees) }\end{array}$ & $\begin{array}{c}\text { Seat Height } \\
(\text { SAE H30) } \\
(\mathrm{mm})\end{array}$ & $\begin{array}{c}\text { Belt } \\
\text { Anchorage } \\
\text { Location }\end{array}$ \\
\hline 1 & Rigid & Unrestricted & 14.5 & 270 & Mid \\
$4 *$ & Rigid & Unrestricted & 14.5 & 180 & Fore \\
5 & Rigid & Restricted & 14.5 & 180 & Fore \\
6 & Rigid & Restricted & 14.5 & 180 & Mid \\
7 & Rigid & Restricted & 14.5 & 180 & Aft \\
8 & Rigid & Unrestricted & 14.5 & 180 & Aft \\
9 & Rigid & Unrestricted & 14.5 & 360 & Aft \\
10 & Rigid & Unrestricted & 14.5 & 360 & Fore \\
11 & Rigid & Unrestricted & 7.5 & 270 & Fore \\
12 & Rigid & Unrestricted & 7.5 & 270 & Aft \\
13 & Rigid & Unrestricted & 7.5 & 270 & Mid \\
14 & Rigid & Unrestricted & 18 & 270 & Mid \\
15 & Rigid & Unrestricted & 18 & 270 & Aft \\
16 & Rigid & Unrestricted & 18 & 270 & Fore \\
\hline$*$ Conditions 2 and 3 used an alternative buckle and are not included in this analysis.
\end{tabular}

\section{Torso Matrix}

The torso test conditions were obtained by placing the D-ring at locations in a rectangular volume illustrated in Figure 3. Potential D-ring positions were identified by three YZ (frontal) planes located 100, 252, and $431 \mathrm{~mm}$ aft of the H-point. Within each plane, 9 possible D-ring positions were defined in an area $117 \mathrm{~mm}$ tall and $88 \mathrm{~mm}$ wide. The large test matrix, used in one test block (see below), included the $15 \mathrm{D}$-ring positions shown in Figure 3 and listed in Table 2. The small test matrix, shown in Figure 4 and listed in Table 3, included 9 D-ring positions, eight of which were also in the large test matrix. Figure 5 illustrates the small matrix with a human volunteer. 


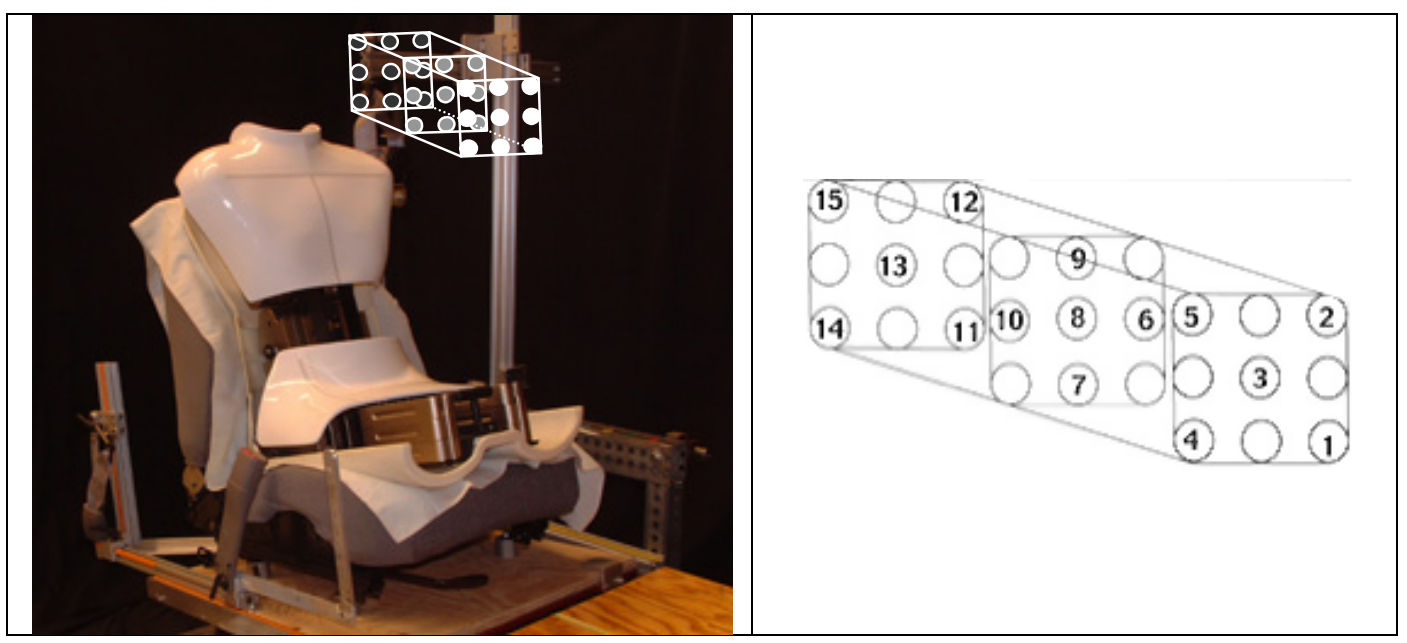

Figure 3. Large torso test matrix. Filled black circles indicate D-ring positions used in testing. Illustration is not to scale. See Table 2 for actual D-ring locations. 
Table 2

Test Conditions for Large Torso Test Matrix

\begin{tabular}{|c|c|c|c|}
\hline \multirow{2}{*}{$\begin{array}{l}\text { Condition } \\
\text { Number }\end{array}$} & \multicolumn{3}{|c|}{ D-ring Bolt re $\mathrm{H}$ point (mm) } \\
\hline & X (rearward) & $Y$ (right)* & $\mathrm{Z}$ (above) \\
\hline 1 & 100 & -285 & 580 \\
\hline 2 & 100 & -285 & 697 \\
\hline 3 & 100 & -240 & 628 \\
\hline 4 & 100 & -197 & 580 \\
\hline 5 & 100 & -197 & 697 \\
\hline 6 & 252 & -285 & 628 \\
\hline 7 & 252 & -240 & 580 \\
\hline 8 & 252 & -240 & 628 \\
\hline 9 & 252 & -240 & 697 \\
\hline 10 & 252 & -197 & 628 \\
\hline 11 & 431 & -285 & 580 \\
\hline 12 & 431 & -285 & 697 \\
\hline 13 & 431 & -240 & 628 \\
\hline 14 & 431 & -197 & 580 \\
\hline 15 & 431 & -197 & 697 \\
\hline
\end{tabular}

* More-negative Y axis values are further to the left of the occupant. 

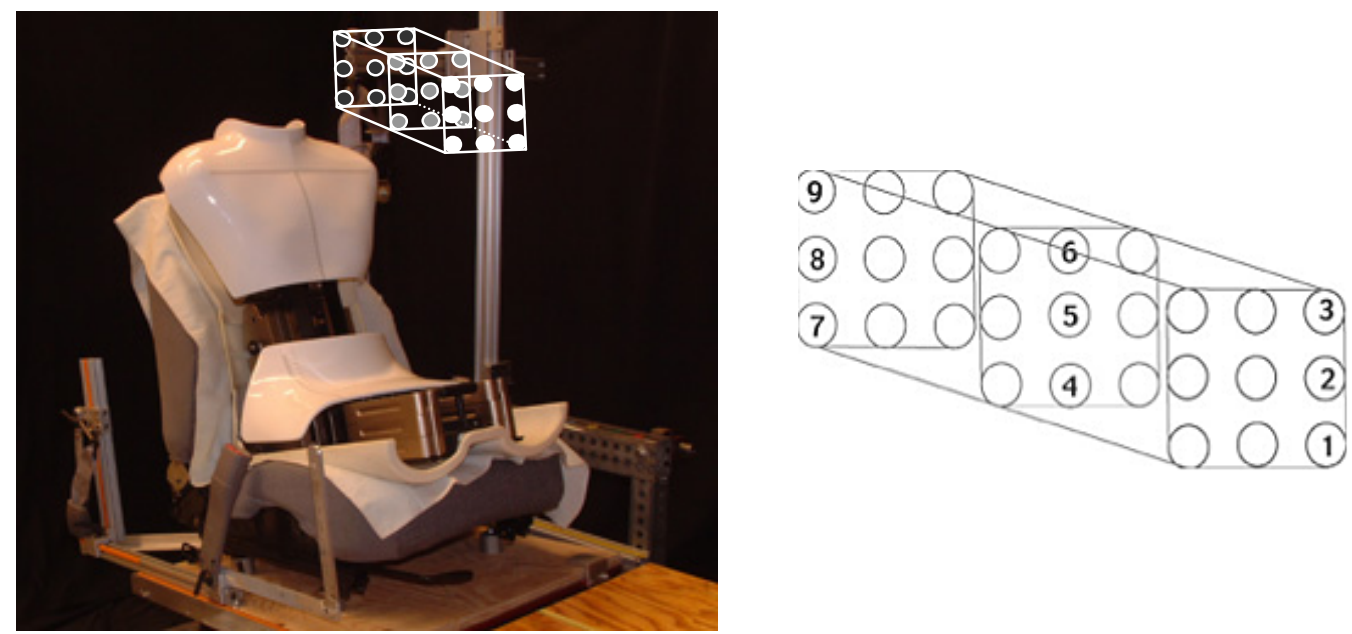

Figure 4. Small torso test matrix. Filled black circles indicate D-ring positions used in testing. Illustration is not to scale. See Table 3 for actual locations.

Table 3

Test Conditions for Small Torso Test Matrix

\begin{tabular}{|c|ccc|}
\cline { 2 - 4 } \multicolumn{1}{c|}{} & \multicolumn{3}{|c|}{ D-ring Bolt re H point $(\mathrm{mm})$} \\
\hline $\begin{array}{c}\text { Condition } \\
\text { Number }\end{array}$ & X (rearward) & Y (right)* & X (rearward) \\
\hline 1 & 100 & -285 & 580 \\
2 & 100 & -285 & 628 \\
3 & 100 & -285 & 697 \\
4 & 252 & -240 & 580 \\
5 & 252 & -240 & 628 \\
6 & 252 & -240 & 697 \\
7 & 431 & -197 & 580 \\
8 & 431 & -197 & 628 \\
9 & 431 & -197 & 697 \\
\hline
\end{tabular}

* More negative $\mathrm{Y}$ axis values are further to the left of the occupant.

Torso testing was conducted in three seatback-angle conditions. Seat back angle was determined using the SAE J826 H-point manikin (manikin torso angle, SAE A40). The large torso matrix was used with a sitter-selected seatback angle, and the small torso matrix was used with the seatback set to 18 and 27 degrees. For all three blocks of back angle conditions, the seat cushion angle was set to the middle position (14.5 degrees) and the seat height was set to the middle height $(270 \mathrm{~mm})$. During torso testing, the stalkmounted buckle was used with the buckle and outboard anchorages set to the middle position (see Table 4). 


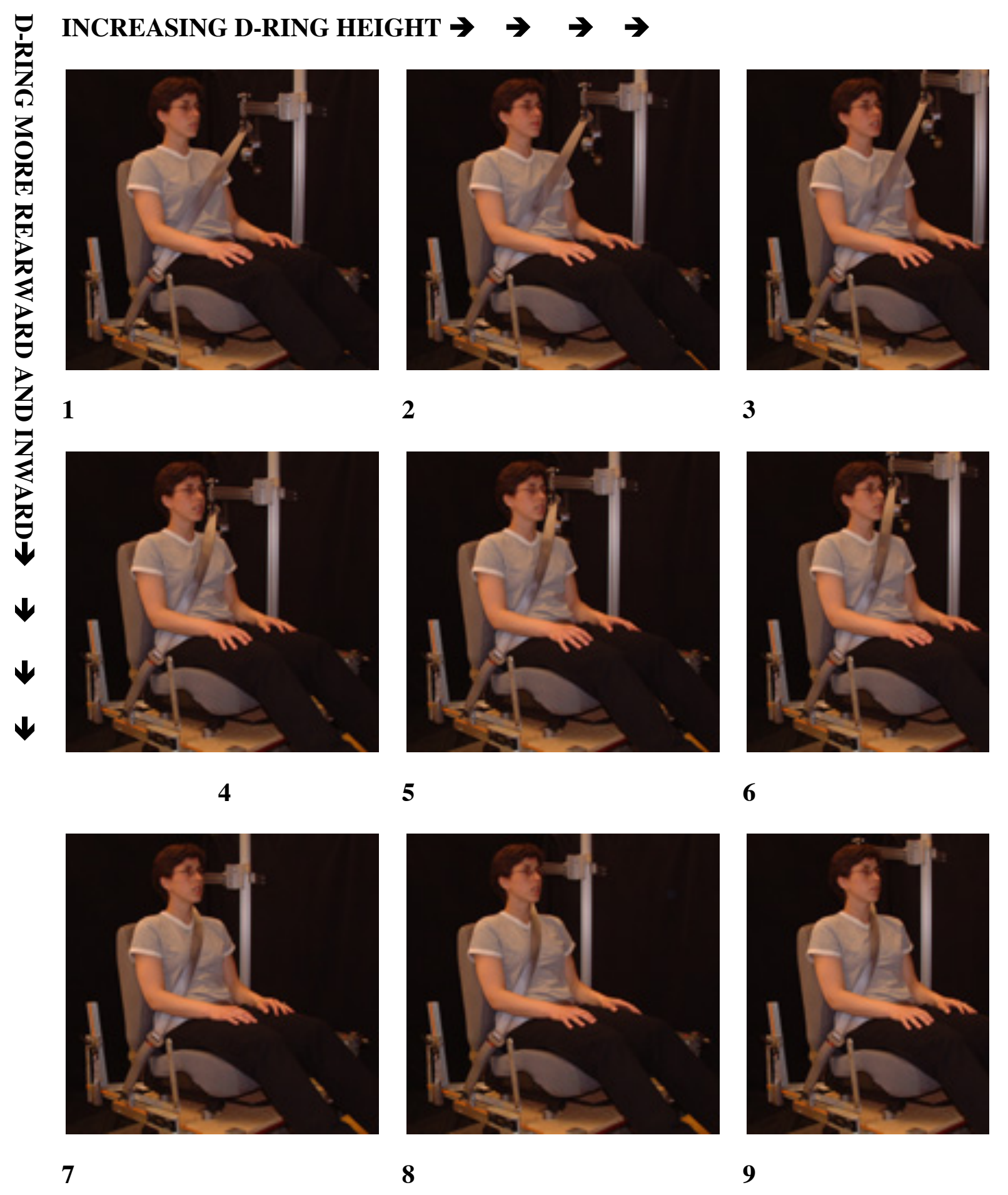

Figure 5. Illustration of D-ring positions for small torso test matrix, showing the wide range of torso belt fit produced by the test conditions. 


\section{Landmarks Used to Characterize Sitter Posture and Belt Fit}

In each test condition, a series of body landmarks were digitized to record the sitter's posture and the routing of the belt. The points in Table 4, which span the left side of the sitter's body, were digitized at the start of each test block. A smaller set of points was digitized each time the participant donned the belt. Table 5 lists the landmarks that were recorded during testing with the torso matrix. Because leg posture changed across lap belt trials, the landmarks in Table 4 were recorded for each lap belt trial. Table 6 lists the points recorded on the belt during the lap trials. In addition to the point-location measurements, streams of points were recorded along the edge of the belt in trial 6 to characterize the length and route of the belt. In each back angle block of the torso belt matrix, streams were recorded at the middle D-ring position, condition 8 in the large matrix and condition 5 in the small matrix. In each cushion angle block with a seat height of $270 \mathrm{~mm}$, streams were recorded with the lower anchorages set to the middle position, conditions 1,13 and 14 .

Table 4

Body Landmarks to Characterize Sitting Posture

1. Top of head

2. Back of head

3. C7

4. Glabella

5. Infraorbitale

6. Corner of eye

7. Tragion

8. Acromion
9. Clavicle, lateral

10. Clavicle, medial

11. Suprasternale

12. Substernale

13. Lateral epicondyle

14. Wrist

15. ASIS Left

16. ASIS Right
17. Pubic symphysis

18. Patella

19. Lateral femoral condyle

20. Lateral malleolus

21. Heel rest point

22. Ball of shoe

Table 5

Points Recorded During Each Torso Trial

1. Dring bolt

2. Divot on D-ring Fore

3. Divot on D-ring Aft

4. Belt - Clavicle outboard

5. Belt - Clavicle inboard
6. Belt - Belt leaves body

7. Belt - Sternum top

8. Belt - Sternum bottom

9. Latch-plate fore

10. Latch-plate aft
11. Acromion

12. Clavicle lateral

13. Clavicle medial

14. Supersternale

15. Substernale

Table 6

Points Recorded During Each Lap Trial*

1. Latch-plate fore

2. Latch-plate aft

3. Top edge of belt at ASIS lateral position (right and left)

*In additional to points listed in Table 8
4. Bottom edge of belt at ASIS lateral position (right and left)

5. Inboard lower anchorage bolt

6. Outboard lower anchorage reference

\section{Test Protocol}

Participants were recruited by newspaper advertisements and from lists of participants in previous studies. The newspaper ads solicited people who were "overweight" and 
"concerned about seat belt fit." Participants who were selected for testing completed a written consent form. Testing was conducted in an UMTRI laboratory and lasted for about two hours. Participants wore normal indoor clothing.

Torso belt conditions were conducted as three back angles of blocks of $18^{\circ}, 27^{\circ}$ and sitter-selected, and lap belt conditions were presented as one block. The order of the four blocks was randomized. The order of presentation of test conditions within each block was also randomized with seat heights randomized within cushion angle blocks.

Prior to testing in each back-angle block, the investigator configured the seat to the appropriate condition, setting the seat back angle, seat height, and seat cushion angle. If the sitter was to select the back angle, the back angle was initially set to 23 degrees. The participant sat in the seat and assumed a comfortable posture with knees extended, heels resting on the floor, and hands resting on the tops of his or her thighs. The investigator recorded the whole-body posture landmarks listed in Table 4, then set the D-ring location to the first test condition. The sitter was instructed to reach for the belt, don and buckle the belt, and then to resume a relaxed sitting posture, looking straight ahead. The investigator digitized the landmarks in Table 5. The participant unbuckled and stowed the belt, after which the investigator positioned the D-ring for the next trial. The participant remained in the seat during each back-angle block.

For the lap matrix, the trials were blocked by seat cushion angle. The participant remained in the seat during the trials at each seat cushion angle. Trials were randomized within each cushion-angle block, and the order of cushion-angle blocks was randomized.

\section{Subject Anthropometry}

Figure 6 shows subject BMI $\left(\mathrm{kg} / \mathrm{m}^{2}\right)$ relative to stature for men $(\mathrm{N}=27)$ and women $(\mathrm{N}=27)$. The median age was 55 years and 26 of $54(48 \%)$ were obese $(\mathrm{BMI} \geq 30)$. Stature ranged from less than the $5^{\text {th }} \%$ ile for U.S. adult women (approximately $1510 \mathrm{~mm}$ ) to more than the $95^{\text {th }} \%$ ile for U.S. men (approximately $1875 \mathrm{~mm}$ ). 


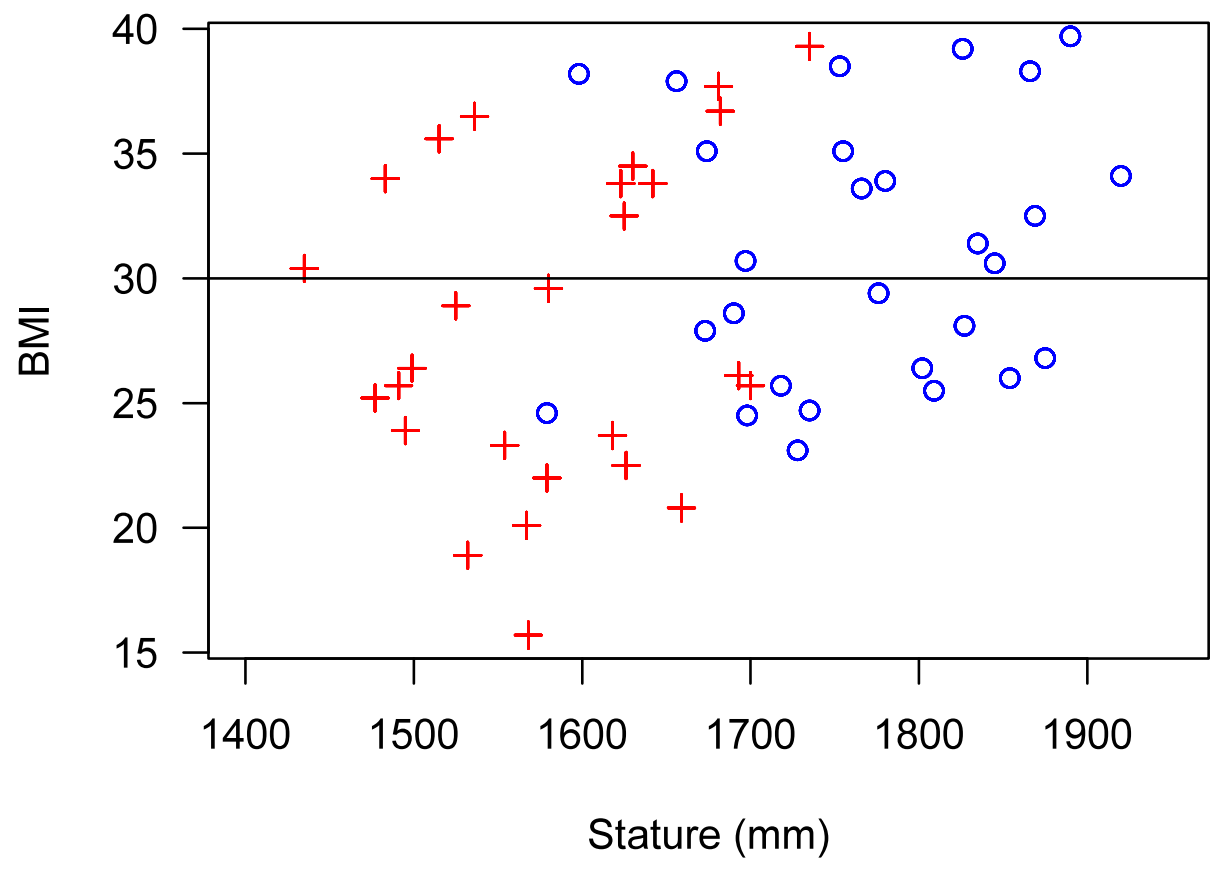

Figure 6. Body mass index $\left(\mathrm{kg} / \mathrm{m}^{2}\right)$ versus stature for men (o) and women (+). BMI $\geq 30 \mathrm{~kg} / \mathrm{m}^{2}$ is considered obese.

\section{Dependent Measures and Statistical Analysis}

Belt fit measures were similar to those used previously for quantifying belt fit on child occupants (Reed et al. 2009). Lap belt fit was assessed by quantifying the location of the upper edge of the lap belt at the lateral location of the right and left anterior-superior iliac spine (ASIS) landmarks on the pelvis. The measurements were expressed relative to the ASIS location in side view, as shown in Figure 7. The fore-aft (X) and vertical (Z) location is positive rearward and above the ASIS landmark location. The length of the lap belt webbing from the latchplate to the outer anchorage was also quantified. In three conditions $(1,13$, and 14), a stream of approximately 100 points was recorded along the upper edge of the belt. These conditions are defined by a seat height of $270 \mathrm{~mm}$, the middle belt anchorage location with the rigid stalk, and cushion angles of 7.5, 14.5, and 18 degrees. A third-order Bezier curve was fit to the stream points to smooth measurement error and the length of the resulting curve was calculated. 


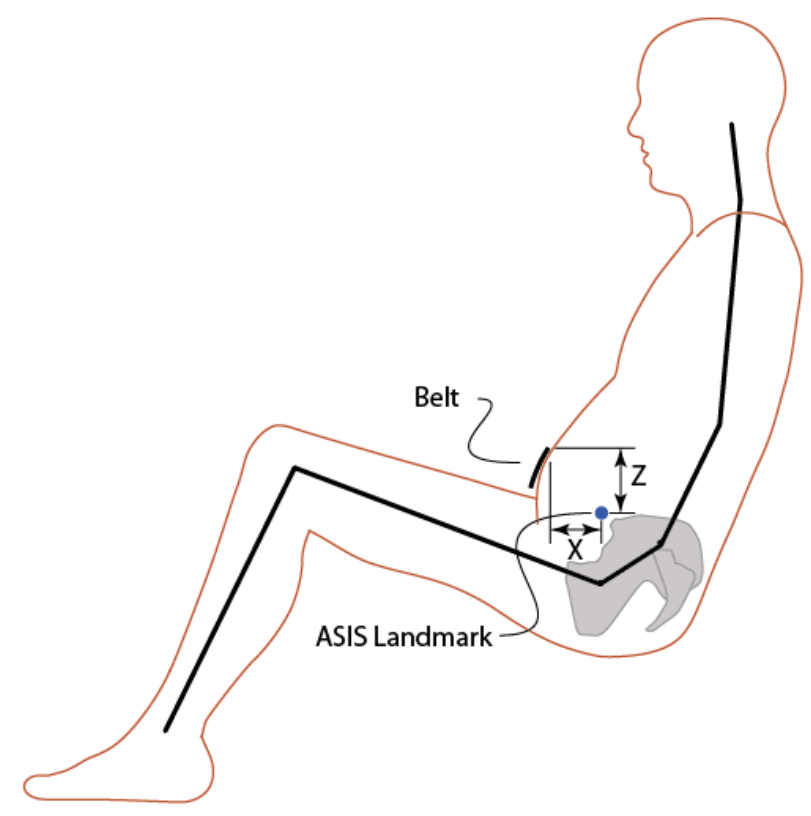

Figure 7. Dependent measures for lap belt fit. The upper/rearward edge of the lap portion of the belt is measured at the lateral position of the right and left anterior-superior iliac spine (ASIS) landmark. The foreaft $(\mathrm{X})$ coordinate is positive rearward of the ASIS and the vertical coordinate is positive above the ASIS landmark.

The fit of the torso portion of the belt was quantified by calculating the location of the inboard edge of the belt at the height of the suprasternale landmark. Figure 8 shows this dimension, which is positive when the inboard edge of the belt lies outboard of the suprasternale landmark. The length of the belt webbing from the D-ring to the latchplate was also recorded in two conditions, using a single midrange D-ring location and 18degree, 27-degree, and sitter-selected seat back angles. 


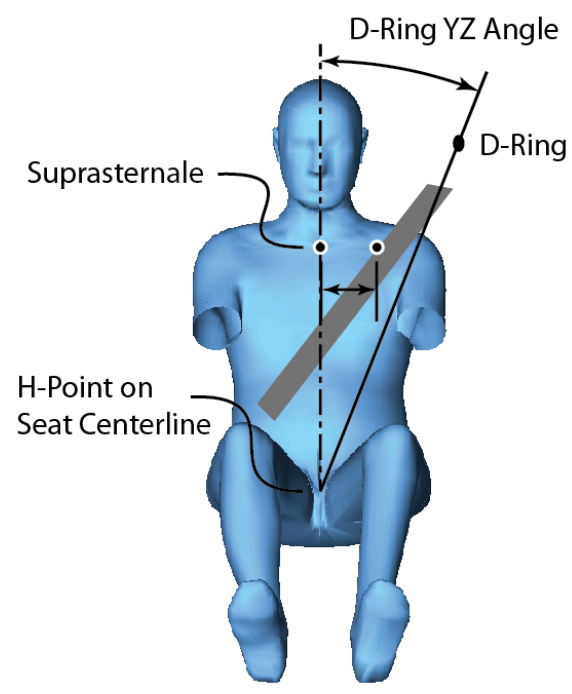

Figure 8. Torso (shoulder) belt fit measurement. Larger positive values indicate more-outboard belt placement. The definition of D-ring YZ Angle is also shown.

Statistical analyses were conducted using the R software package version 2.7.2 (rproject.org). Some analyses were conducted on subsets of the data to obtain orthogonal and balanced designs (see results). For analyses considering the continuous effects of belt anchorage locations, lap belt angle was calculated using the measured lower anchorage locations and the seat H-point, using the definitions in FMVSS 210. For analysis of upper anchorage (D-ring) location, the D-ring location was quantified using two angles. The D-ring YZ angle is the front-view angle of a line from $\mathrm{H}$-point on seat centerline to the D-ring with respect to vertical (Figure 8). The D-ring XZ angle is the angle of the same in side view with respect to vertical. 


\section{RESULTS}

\section{Lap Belt Fit}

Figure 9 shows the belt location relative to right (inboard) ASIS across all lap-belt-matrix trials. The lap belt location was an average of $40 \mathrm{~mm}$ further forward and $22 \mathrm{~mm}$ higher relative to the pelvis for obese participants $(\mathrm{p}<0.001)$, on both the inboard and outboard sides. A linear regression analysis on the inboard lap belt data demonstrated that stature, $\mathrm{BMI}$, and lap belt angle had significant $(\mathrm{p}<0.001)$ effects on both the $\mathrm{X}$ and $\mathrm{Z}$ locations (Tables 7 and 8). After accounting for stature, gender did not have a significant effect. Increasing the lap belt angle from 30 to 80 degrees (steeper) shifted the lap belt an average of $37 \mathrm{~mm}$ forward and $24 \mathrm{~mm}$ lower relative to the pelvis. A BMI value 10 $\mathrm{kg} / \mathrm{m}^{2}$ higher was associated with a lap belt position $43 \mathrm{~mm}$ further forward and $21 \mathrm{~mm}$ higher relative to the pelvis. Stature had a smaller effect, with statures $100 \mathrm{~mm}$ higher associated with a belt position about $4 \mathrm{~mm}$ rearward and $5 \mathrm{~mm}$ lower. Figure 10 shows the BMI effect relative to the lap belt anchorage location, demonstrating that the BMI effect is larger than the belt anchorage effect across the ranges studied, and the effect of $\mathrm{BMI}$ is independent of lap belt anchorage location.
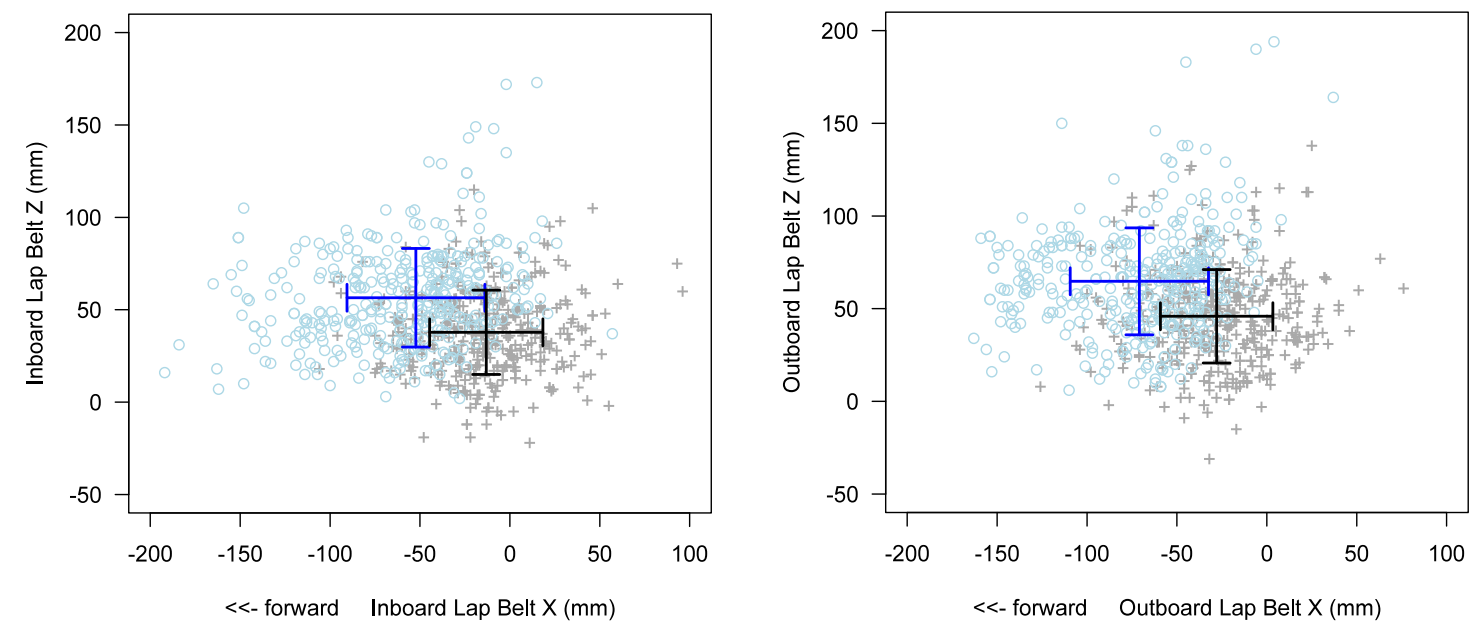

Figure 9. Lap belt location relative to ASIS landmark on the inboard (buckle) side for obese (o, blue) and non-obese $(+$, black) participants in all lap-belt-matrix trials. Bars shown mean \pm one standard deviation by obesity group. 
Table 7

Linear Regression Model for All Lap Matrix Conditions: Lap Belt X (mm) $\mathrm{R}^{2} \operatorname{adj}=0.46, \mathrm{RMSE}=31.2$

\begin{tabular}{lrrrr} 
& \multicolumn{1}{c}{ Estimate } & \multicolumn{1}{l}{ Std. Error } & \multicolumn{1}{l}{ t value } & $\operatorname{Pr}(>|\mathrm{t}|)$ \\
(Intercept) & 70.13367 & 15.615849 & 4.491 & $<0.0001$ \\
BMI $\left(\mathrm{kg} / \mathrm{m}^{2}\right)$ & -4.291721 & 0.198074 & -21.667 & $<0.0001$ \\
Stature $(\mathrm{mm})$ & 0.038128 & 0.009509 & 4.01 & $<0.0001$ \\
Lap Belt Angle (deg) & -0.742974 & 0.056459 & -13.159 & $<0.0001$
\end{tabular}

Table 8

Linear Regression Model for All Lap Matrix Conditions: Lap Belt Z (mm)

$\mathrm{R} 2 \mathrm{adj}=0.35, \mathrm{RMSE}=21.4$

\begin{tabular}{lrrrr} 
& Estimate & Std. Error & \multicolumn{1}{c}{ t value } & $\operatorname{Pr}(>|\mathrm{t}|)$ \\
$($ Intercept $)$ & 88.157323 & 10.69708 & 8.241 & $<0.0001$ \\
BMI $\left(\mathrm{kg} / \mathrm{m}^{2}\right)$ & 2.12755 & 0.135683 & 15.68 & $<0.0001$ \\
Stature $(\mathrm{mm})$ & -0.046227 & 0.006514 & -7.097 & $<0.0001$ \\
Lap Belt Angle (deg) & -0.48146 & 0.038676 & -12.449 & $<0.0001$
\end{tabular}
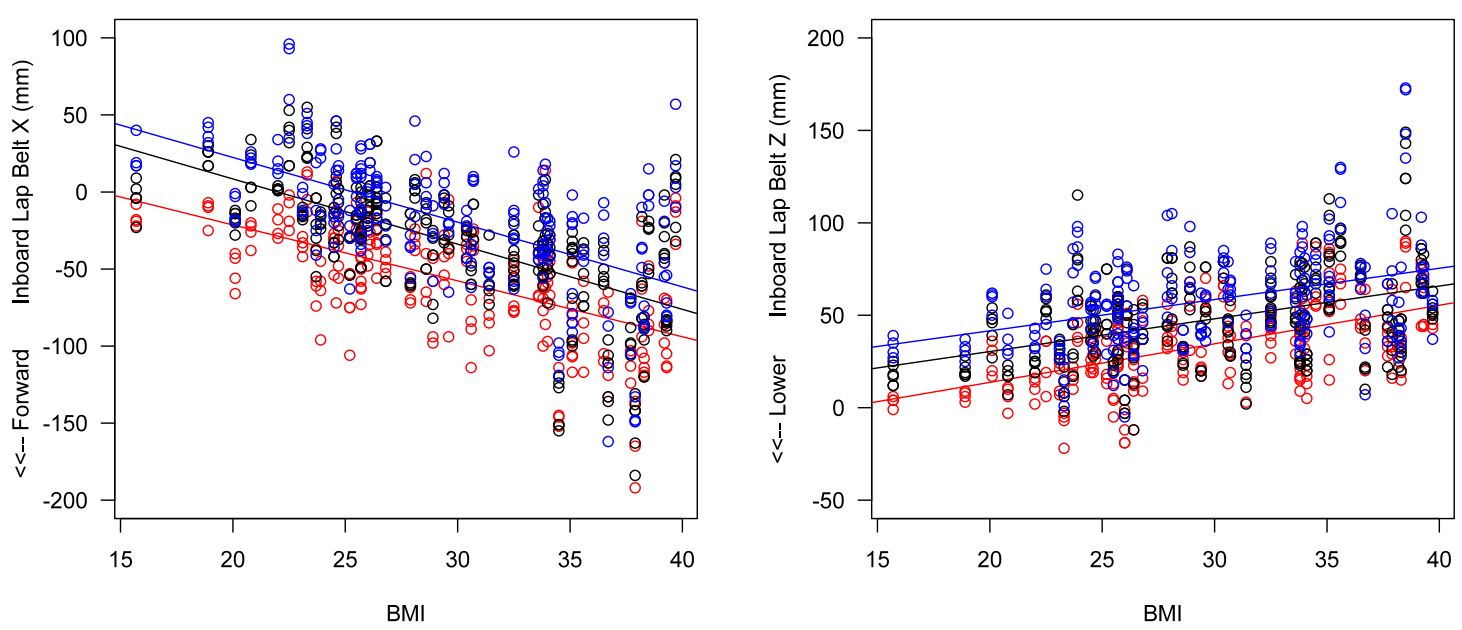

Figure 10. Effects of BMI and lap belt anchorage location (fore $=$ red, mid $=$ black, rear $=$ aft $)$ on lap belt position with respect to the pelvis for all trials with unrestricted foot position. 
In a submatrix orthogonal in foot position and belt anchorage location (conditions 4, 5, 7, and 8), foot position had a significant interaction with BMI $(\mathrm{p}<0.01)$ in analysis of vertical lap belt position. As shown in Figure 11, restricting foot position (feet flat on the floor and rearward) raised the belt relative to the pelvis, and the effect was larger for obese participants. For the fore-aft belt position, the belt was further rearward in the restricted foot position condition, but the interaction with BMI was not significant.

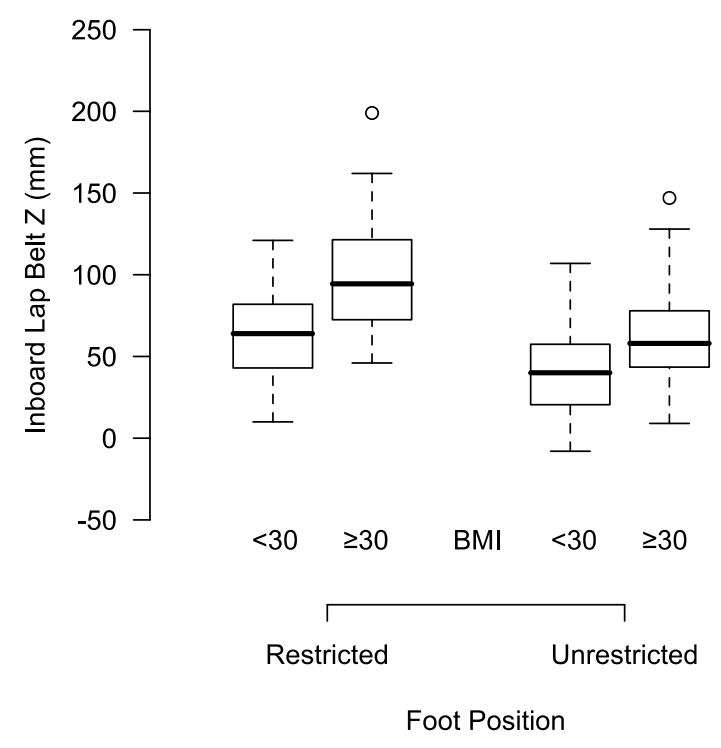

Figure 11. Effects of foot-position restriction on vertical belt location by BMI group.

BMI was strongly associated with the lap belt webbing length $\left(\mathrm{p}<0.001, \mathrm{R}^{2}=0.72\right)$. Figure 12 shows a linear trend, with an increase of $10 \mathrm{~kg} / \mathrm{m}^{2}$ associated with an increase of $130 \mathrm{~mm}$ in lap belt length for the single belt anchorage location (middle) for which belt length was measured. Seat cushion angle did not have a significant effect on lap belt length. 


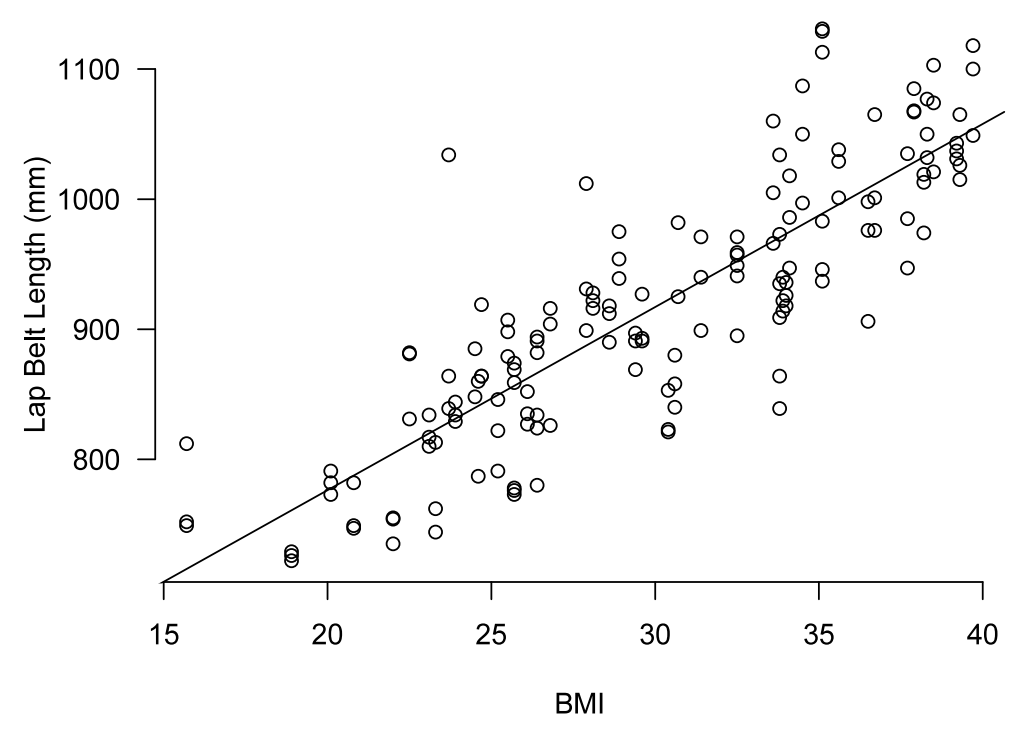

Figure 12. Association between BMI and lap belt length in trials with three cushion angles. The effect of cushion angle was not significant.

\section{Torso Belt Fit}

In linear regression analysis of shoulder belt score using all torso-matrix trials, significant effects of D-ring location ( $\mathrm{YZ}$ and $\mathrm{XZ}$ angles), seat back angle, stature, and BMI were observed (Table 9). A significant interaction between BMI and D-ring YZ angle was observed, but removing the interaction created a simpler model (Table 10) with an adjusted $\mathrm{R}^{2}$ value only 0.002 lower.

However, the residual variance was considerable, with an adjusted $\mathrm{R}^{2}$ value for the model of only 0.37 and root-mean-square error of $28.6 \mathrm{~mm}$. The effect of BMI was modest, with an increase of BMI of $10 \mathrm{~kg} / \mathrm{m}^{2}$ associated with a shoulder belt location $15 \mathrm{~mm}$ more inboard (about one half of the residual standard deviation). As expected, increased D-ring YZ Angle was associated with larger (more outboard) shoulder belt scores, and higher D-ring XZ Angle was associated with lower (more inboard) shoulder belt scores. 
Table 9

Effects of D-ring Location and Subject Covariates on Shoulder Belt Score with Interaction (mm) $\mathrm{R}^{2} \mathrm{adj}=0.371, \mathrm{RMSE}=28.6 \mathrm{~mm}$

(Intercept)

Seat Back Angle (deg)

BMI $\left(\mathrm{kg} / \mathrm{m}^{2}\right)$

Stature $(\mathrm{mm})$

D-ring YZ Angle (deg)

D-ring XZ Angle (deg)

BMI*D-ring YZ Angle

\begin{tabular}{rrrr}
\multicolumn{1}{c}{ Estimate } & Std. Error & \multicolumn{1}{l}{$\mathrm{t}$ value } & $\operatorname{Pr}(>|\mathrm{t}|)$ \\
-138.800 & 21.670 & -6.408 & $<0.0001$ \\
-1.018 & 0.155 & -6.562 & $<0.0001$ \\
0.449 & 0.649 & 0.691 & 0.48935 \\
0.071 & 0.006 & 12.122 & $<0.0001$ \\
7.332 & 0.972 & 7.539 & $<0.0001$ \\
-0.578 & 0.076 & -7.626 & $<0.0001$ \\
-0.096 & 0.032 & -2.992 & 0.00281
\end{tabular}

Table 10

Effects of D-ring Location and Subject Covariates on Shoulder Belt Score without Interaction ( $\mathrm{mm}$ ) $\mathrm{R}^{2} \mathrm{adj}=0.369, \mathrm{RMSE}=28.6 \mathrm{~mm}$

(Intercept)

Seat Back Angle (deg)

BMI $\left(\mathrm{kg} / \mathrm{m}^{2}\right)$

Stature $(\mathrm{mm})$

D-ring YZ Angle (deg)

D-ring XZ Angle (deg)

\begin{tabular}{rrrl} 
Estimate & Std. Error & \multicolumn{1}{l}{$\mathrm{t}$ value } & $\operatorname{Pr}(>|\mathrm{t}|)$ \\
-83.344 & 11.224 & -7.425 & $<0.0001$ \\
-1.012 & 0.155 & -6.510 & $<0.0001$ \\
-1.461 & 0.118 & -12.410 & $<0.0001$ \\
0.071 & 0.006 & 12.161 & $<0.0001$ \\
4.495 & 0.217 & 20.708 & $<0.0001$ \\
-0.574 & 0.076 & -7.561 & $<0.0001$
\end{tabular}

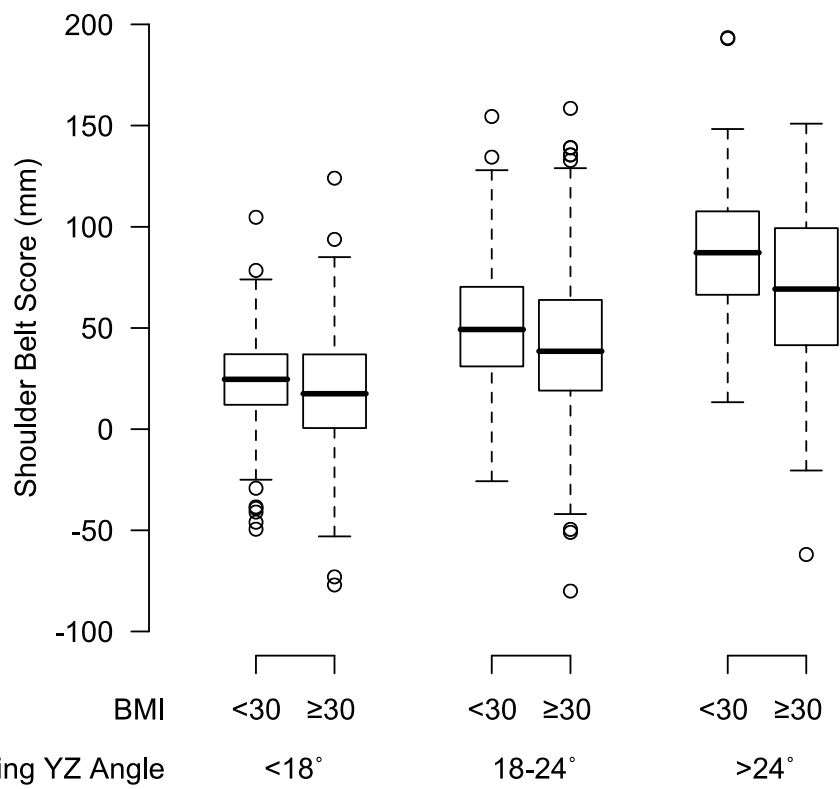

Figure 13. Effect of BMI on shoulder belt score by D-ring YZ angle level. 
The seat belt webbing length between the D-ring and latchplate was measured in three trials, each with the same D-ring location and with back angles of 18 degrees, 27 degrees, and sitter-selected. Figure 14 shows strong relationships between BMI and torso belt length, dependent on back angle. Tables 11 and 12 show the regression results with and without the interaction, which has only a small effect on the model fit. On average, an increase in BMI of $10 \mathrm{~kg} / \mathrm{m}^{2}$ is associated with $60 \mathrm{~mm}$ of additional belt webbing length between the D-ring and latchplate. For the study population and belt configurations, this corresponds to a $7.4 \%$ increase relative to a mean webbing length of $816 \mathrm{~mm}$.

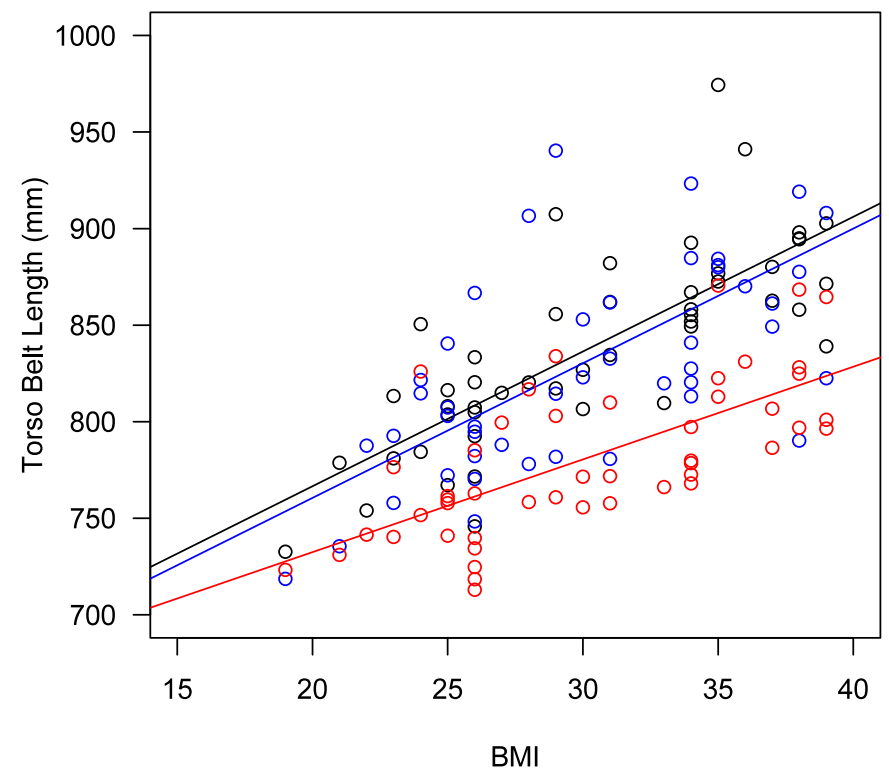

Figure 14. Relationship between BMI and torso belt length for back angles 18 degrees (black), 27 degrees (red) and sitter-selected (blue).

Table 11

Effects of BMI and Seat Back Angle (SAE A40) on Torso Belt Length (mm) $\mathrm{R}^{2} \mathrm{adj}=0.677, \mathrm{RMSE}=31.9 \mathrm{~mm}$

(Intercept)

BMI $\left(\mathrm{kg} / \mathrm{m}^{2}\right)$

Seat Back Angle (deg)

BMI*Seat Back Angle

\begin{tabular}{rrrr} 
Estimate & Std. Error & \multicolumn{1}{l}{$\mathrm{t}$ value } & $\operatorname{Pr}(>|\mathrm{t}|)$ \\
598.4246 & 86.6047 & 6.91 & $<0.0001$ \\
12.4795 & 2.7934 & 4.467 & $<0.0001$ \\
1.4266 & 3.6331 & 0.393 & 0.6952 \\
-0.2746 & 0.1174 & -2.339 & 0.0208
\end{tabular}


Table 12

Effects of BMI and Seat Back Angle (SAE A40) on Torso Belt Length without Interaction (mm) $\mathrm{R}^{2} \mathrm{adj}=0.667, \mathrm{RMSE}=32.4 \mathrm{~mm}$

(Intercept)

BMI $\left(\mathrm{kg} / \mathrm{m}^{2}\right)$

Seat Back Angle (deg)

\begin{tabular}{rrrl}
\multicolumn{1}{l}{ Estimate } & Std. Error & \multicolumn{1}{l}{$\mathrm{t}$ value } & $\operatorname{Pr}(>|\mathrm{t}|)$ \\
794.952 & 21.3322 & 37.27 & $<0.0001$ \\
6.0445 & 0.4921 & 12.28 & $<0.0001$ \\
-6.9487 & 0.6252 & -11.11 & $<0.0001$
\end{tabular}




\section{DISCUSSION}

This study provides the first documentation of the effects of obesity on seat belt fit. Obese sitters on average experienced markedly poorer lap belt fit than the non-obese participants. Given that the typical belt webbing width is $48 \mathrm{~mm}$, the average difference in fore-aft lap belt location relative to the pelvis for two individuals differing in BMI by $10 \mathrm{~kg} / \mathrm{m}^{2}$ is approximately $75 \%$ of the belt width, and the belt rides higher by about $50 \%$ of the belt width for the obese sitters.

The results indicate two ways in which belts are likely to be less effective for obese occupants. The higher and more-forward positioning of the lap belt makes it more likely that the belt will fail to engage the pelvis as the occupant slides forward during a frontal crash. Without pelvis restraint from the belt, the occupant's knees will impact the underside of the instrument panel with greater speed and force, and the belt will deform and possibly injure abdominal organs. This poor control of the lower body may also make abdomen or thorax contact with the steering wheel rim more likely. Second, the greater length of belt webbing observed with increased BMI is essentially belt slack that must be taken up by occupant excursion before the belt can be effective. This increased excursion puts the occupant at greater risk for head contact with the interior and, as with poor lap belt placement, increases the risk of lower-extremity injury.

The results show that increased BMI affects lap belt fit more than lap belt angle, which is the main design variable used to influence lap belt performance (Figure 10). That is, occupant factors may be more important in determining the performance of the lap belt system than the system design variables. Increased BMI compounds the decrement in lap belt fit associated with foot position restriction. These results suggest that obese occupants will experience particularly poor lap belt fit in rear-seat conditions where lack of legroom causes elevated-knee postures.

Shoulder belt fit was not strongly affected by obesity, particularly when compared with the effects of D-ring location. However, belt-webbing length in the torso portion of the belt was increased, suggesting more belt slack. However, the increase in webbing length in the torso portion was less than in the lap portion, which may have the effect of worsening occupant kinematics in a frontal crash. That is, the torso may be restrained earlier in the crash than the pelvis, leading to rearward rotation of the torso as the restraint loads increase, a motion opposite from the ideal kinematic pattern (Adomeit et al. 1975).

These results suggest some ways that restraint systems might be optimized for obese occupants. If in-vehicle sensing systems were able to determine that the occupant was obese (perhaps by comparing data from seat-positioning and belt-webbing-length measurements), potential countermeasures include increasing the stroke of belt pretensioning systems, increasing the threshold for belt load limiters, and altering the deployment characteristics of steering-wheel and knee airbags. Efforts to optimize restraint system performance for obese occupants must take into account the effects of seat position and sitting posture on the restraint geometry relative to the occupant, as well as the biomechanical tolerance of the tissues underlying the belt. 


\section{Limitations}

This study was conducted in the laboratory, so the effects of dynamic ride motions could not be considered. In general, ride motions would be expected to worsen lap belt fit, particularly in vehicles with sliding latchplates like the one used in this study. A single belt and buckle design was used, although it is typical of contemporary vehicles. The results do not take into account posture shifts that people might use to reduce discomfort due to shoulder belt contact with the neck. The participants wore light clothing; heavy clothing might further worsen belt fit. The seat used in this study was designed and built in the mid-1990s. However, the design is substantially similar to many seats used today, and the calibration of the test conditions to seat H-point means that the idiosyncrasies of this particular seat are unlikely to meaningfully affect the generalizability of the results. Data were recorded with the participants in a comfortable riding posture. Arm and leg postures associated with driving might affect the results, probably by worsening lap belt fit and improving shoulder belt fit.

The current analysis excluded participants with BMI $>40 \mathrm{~kg} / \mathrm{m}^{2}$. Data from the 13 participants in the original study with $\mathrm{BMI} \geq 40$ suggest that belt fit continues to worsen with increasing BMI, but measurement difficulties make quantifying those changes problematic. In particular, accurately locating the pelvis of a morbidly obese occupant is challenging.

\section{CONCLUSIONS}

Obesity worsens lap belt fit significantly, effectively shifting the belt forward and upward relative to the pelvis and adding slack. Shoulder belt fit is not strongly affected, but the belt webbing length between the latchplate and D-ring is increased. The net effect is likely to be a decrease in the effectiveness of the belt restraint for obese occupants. 


\section{REFERENCES}

Adomeit D and Heger A. (1975). Motion sequence criteria and design proposals for restraint devices in order to avoid unfavorable biomechanic conditions and submarining. Paper No. 751146, Society of Automotive Engineers, Warrendale, PA.

Flegal, K.M, Carroll, M.D. Ogden, C.L., and Curtin, L.R. (2010). Prevalence and Trends in Obesity Among US Adults, 1999-2008. JAMA 303(3):235-241.

Kent, R.W., Forman, J.L., and Bolstrom, O. (2010). Is there really a "cushion effect"?: a biomechanical investigation of crash injury mechanisms in the obese. Obesity 18(4):749-753.

Klinich, K.D., Schneider, L.W., Rupp, J.D., Eby, B.H., and Pearlman, M.P. (1999). Challenges in frontal crash protection of pregnant drivers based on anthropometric considerations. SAE Transactions: Journal of Passenger Cars, 108: Paper 990711.

Reed, M.P., Ebert, S. M., Sherwood, C.P., Klinich, K.D., and Manary, M.M. (2009). Evaluation of the static belt fit provided by belt-positioning booster seats. Accident Analysis and Prevention, 41:598-607.

Reed, M.P., Lehto, M.M., Anctil, B., Brown, C., and Noy, I. (2002). Development of seatbelt fit assessment components for the ASPECT manikin. SAE Technical Paper 2002-01-0686. SAE International, Warrendale, PA.

Rupp, J.D., Flannagan, C.A.C, Leslie, A.J., Hoff, C.N., Reed. M.P., and Cunningham, R.M. (2011). Effects of BMI on the Risk and Frequency of Serious Injury in MotorVehicle Crashes. Submitted to Obesity.

SAE (2011). SAE Handbook. SAE International, Warrendale, PA.

Zhu, S., Layde, P.M., Guse, C.E., Purushottam, W.L., Pintar, F., Nirula, R., and Hargarten, S. (2006). Obesity and risk for death due to motor vehicle crashes. Am J Pub Health 96(4):734-739. 